\title{
Abruptly attenuated carbon sequestration with Weddell Sea dense waters towards the end of the 21st century
}

\section{Cara Nissen ( $\sim$ cara.nissen@awi.de )}

Alfred-Wegener-Institut, Helmholtz-Zentrum fuer Polar- und Meeresforschung https://orcid.org/00000001-5804-3191

\section{Ralph Timmermann}

AWI

\section{Mario Hoppema}

Alfred Wegener Institute https://orcid.org/0000-0002-2326-619X

\section{Judith Hauck}

Alfred Wegener Institute, Helmholtz Centre for Polar and Marine Research https://orcid.org/0000-00034723-9652

\section{Article}

Keywords:

Posted Date: December 15th, 2021

DOI: https://doi.org/10.21203/rs.3.rs-934877/v1

License: (c) (1) This work is licensed under a Creative Commons Attribution 4.0 International License. Read Full License

Version of Record: A version of this preprint was published at Nature Communications on June 14th, 2022. See the published version at https://doi.org/10.1038/s41467-022-30671-3. 


\title{
Abruptly attenuated carbon sequestration with Weddell Sea dense waters towards the end of the $21^{\text {st }}$ century
}

\author{
Cara Nissen $^{1 *} \quad$ Ralph Timmermann ${ }^{1} \quad$ Mario Hoppema $^{1} \quad$ Judith Hauck $^{1}$ \\ ${ }^{1}$ Alfred Wegener Institut, Helmholtz Zentrum für Polar- und Meeresforschung, \\ Bremerhaven, Germany \\ *Corresponding author: cara.nissen@awi.de
}

\begin{abstract}
Antarctic Bottom Water formation, such as in the Weddell Sea, is an efficient vector for carbon sequestration on time scales of centuries. Possible changes in carbon sequestration under changing environmental conditions are unquantified to date, mainly due to difficulties in simulating the relevant processes on highlatitude continental shelves. Using a model setup including both ice-shelf cavities and oceanic carbon cycling, we demonstrate that by 2100 , deep-ocean carbon accumulation in the southern Weddell Sea is abruptly attenuated to only $40 \%$ of the rate in the 1990s in a high-emission scenario, while still being 4-fold higher in the 2080s. Assessing deep-ocean carbon budgets and water mass transformations, we attribute this decline to an increased presence of Warm Deep Water on the southern Weddell Sea continental shelf, a $16 \%$ reduction in sea-ice formation, and a $79 \%$ increase in ice-shelf basal melt. Altogether, these changes lower the density and volume of newly formed bottom waters and reduce the associated carbon transport to the abyss.
\end{abstract}


20 Due to its unique setting in the global overturning circulation ${ }^{1}$, the Southern Ocean plays an important role in the partitioning of carbon between the atmosphere and the deep ocean. Early box models ${ }^{2 / 4}$ and later also general ocean circulation models ${ }^{5}$ demonstrated that the formation of Antarctic Bottom Water (AABW) at high southern latitudes facilitates carbon sequestration on centennial to millennial time scales ${ }^{6}$ and therefore exerts a strong control on global atmospheric $\mathrm{CO}_{2}$ concentrations and climate. Despite this recognized importance on climatically relevant time scales ${ }^{2 / 4}$, no quantitative information exists to date about the amount of carbon sequestered during the formation of $A A B W$ and its importance relative to deep carbon accumulation through sinking biotic particles ${ }^{6}$. In fact, the difficulty of ocean models to correctly simulate all processes involved in AABW formation ${ }^{78}$ and the scarcity of observational data in its formation regions on the Antarctic continental shelves ${ }^{9}$ complicate both the assessment of present-day AABW formation and carbon sequestration rates, as well as the detection of climate change impacts. This is true even for the Weddell Sea in the Atlantic sector of the Southern Ocean, which since the 1930s has been recognized as the most important AABW formation region ${ }^{10 \mid 11}$ and is the best observed one to date ${ }^{12}$.

Generally, the formation of AABW can be divided into two steps ${ }^{13+16}$ : First, open-ocean water masses flowing into the southern Weddell Sea on the eastern flank of the cyclonic Weddell Gyre ${ }^{17 / 18}$ are transformed to Dense Shelf Water (DSW) as a result of the buoyancy loss caused by atmosphere-ocean, sea ice-ocean, and ice shelf-ocean interactions ${ }^{14}$ (Fig. 1). The densification of waters thereby predominantly occurs on the southwestern Weddell Sea continental shelf as a result of heat loss and local sea-ice formation; it is to some extent counteracted by precipitation and meltwater fluxes from the Filchner-Ronne and Larsen ice shelves ${ }^{19}-24$. Second, the DSW cascades down the continental slope forming either Weddell Sea Deep Water (WSDW; potential temperature $-0.7^{\circ} \mathrm{C} \leq \theta_{0}<0^{\circ} \mathrm{C}^{17}$ ) or Weddell Sea Bottom Water (WSBW; $\theta_{0}<-$ $0.7^{\circ} \mathrm{C}^{17}$ ). Along the way, Warm Deep Water (WDW; the Weddell Sea variant of Circumpolar Deep Water (CDW) with $\theta_{0}>0^{\circ} \mathrm{C}^{17}$ ) is entrained to ultimately form AABW, which then spreads throughout the abyss of the global ocean ${ }^{13 / 14}$. Integrating observations from 1973-2017, it has recently been suggested that, on average, $4.5 \pm 0.3 \mathrm{~Sv}$ of DSW formed on the Weddell Sea continental shelf in the first step entrain another $3.9 \pm 0.5 \mathrm{~Sv}$ of WDW on its way to the abyss, resulting in a total of $8.4 \pm 0.7 \mathrm{~Sv}$ of AABW transported northwards along the western flank of the Weddell Gyre ${ }^{16}$.

AABW formation in the Weddell Sea is highly variable in time ${ }^{25}-27$ and rather sensitive to changing environmental conditions due to its close ties with buoyancy fluxes and density distributions ${ }^{14227}$. Both WSDW and WSBW have been warming and freshening since the $1980 \mathrm{~s}^{28} \cdot 33$, which has at least partly been attributed to property changes of newly formed DSW26/34 , possibly due to changes in sea-ice formation and ice-shelf basal melt rates in the area ${ }^{32}$. For the $21^{\text {st }}$ century, climate models project a slowdown or even a complete shutdown of AABW formation under the high-emission RCP8.5 scenario ${ }^{7}$, as a consequence of continuous warming and freshening of high-latitude waters ${ }^{35}$. However, limited by the coarse resolution on the Antarctic continental shelves $(\sim 50 \mathrm{~km})$ and the absence of an ice-shelf component, many of these models struggle to correctly reproduce AABW properties ${ }^{836}$ and often form AABW entirely via spurious deep convection in the open ocean rather than via water mass transformations on the Weddell Sea continental shelves south of the World Ocean Circulation Experiment (WOCE) transect SR4, which connects the tip of the Antarctic Peninsula with the eastern Weddell Sea at Kapp Norvegia (Fig. 1 178837 . The reduction of AABW formation in response to the expected large freshwater discharge from ice shelves in the upcoming decades ${ }^{38}$ has recently been confirmed with higher-resolution ocean models, which better capture AABW formation regions on the Antarctic shel| 3940 . These model experiments were, however, highly idealized with prescribed freshwater input at the surface instead of the employment of a dynamic ice-shelf component in the model. While ocean models including such a dynamic calculation of freshwater discharge in ice-shelf cavities project an up to 15 -fold increase in Weddell Sea ice-shelf basal melt rates by the year $2100^{41-46}$, the relative contribution of enhanced ice-shelf basal melt and reduced sea-ice formation $\sqrt{42145}$ to changes in Weddell Sea DSW formation and the implications for carbon transfer to depth remain unquantified.

An improved understanding of Weddell Sea carbon cycling is urgently needed, as observations have revealed substantial changes in carbon cycling in this area over the recent pas ${ }^{9 / 47}: 51$ : While the Weddell Sea was a net source of carbon to the atmosphere in preindustrial times ${ }^{948}$, it is currently a net sink of $\sim 33-80 \mathrm{Tg} \mathrm{C}$ per year ${ }^{4750 \mid 51}$. Even though climate models suggest an up to 4-fold increase in $\mathrm{CO}_{2}$ uptake in the high-latitude Southern Ocean by the end of the $21^{\text {st }}$ century ${ }^{52}$, it is still unclear how these projected changes in air-sea $\mathrm{CO}_{2}$ exchange might affect carbon sequestration in the deep ocean. Here, we fill this gap by using a global ocean-sea ice-biogeochemical mode ${ }^{53 ! 57}$ with a representation of ice-shelf cavities ${ }^{58}$ and an eddy-permitting resolution on the southern Weddell Sea continental shelves. Forcing our ocean model with atmospheric output from the AWI Climate Mode ${ }^{[59}$, the comparison of a high-emission future scenario 


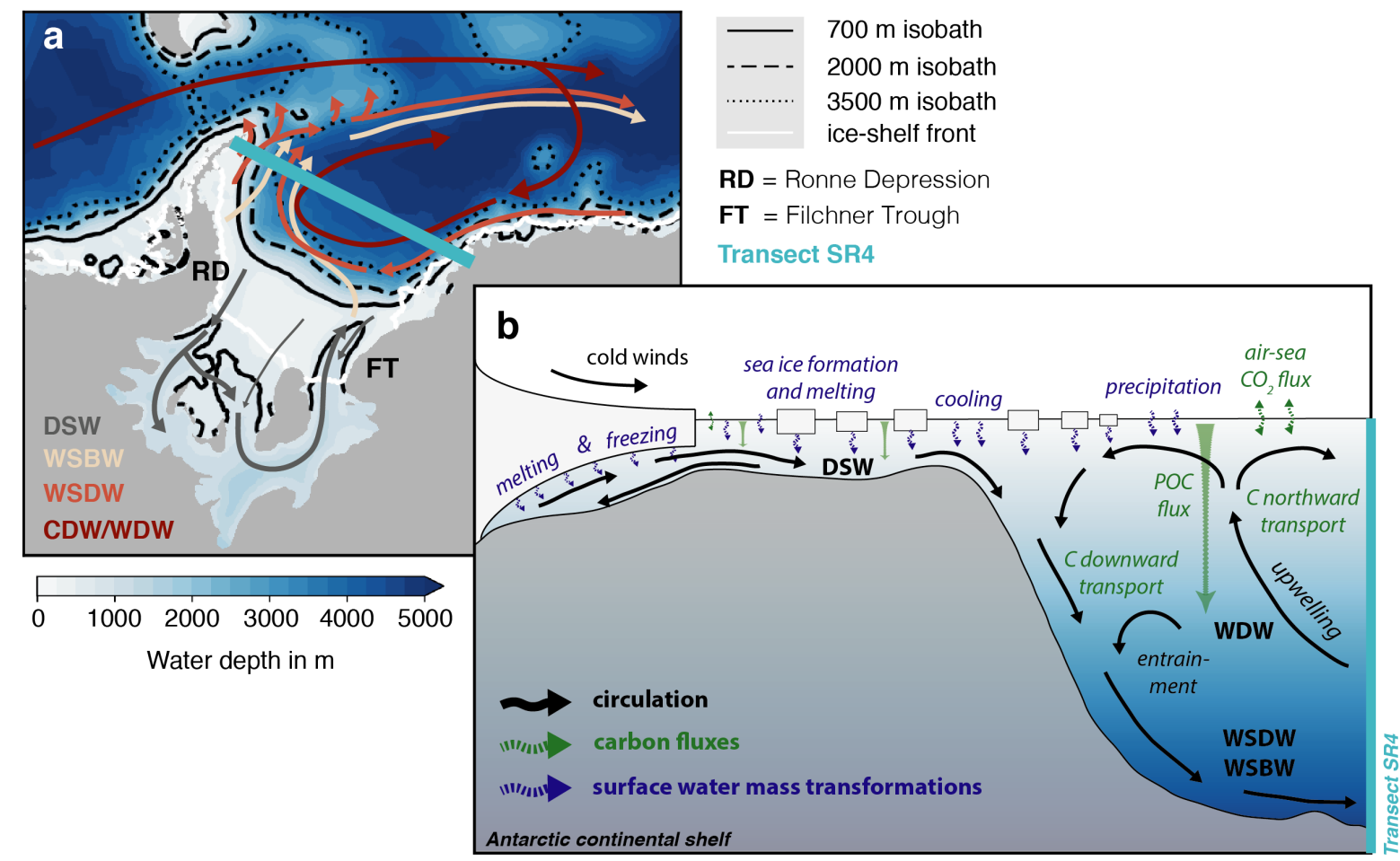

Figure 1: Sketch illustrating the major processes involved. a Water depth in $\mathrm{m}$ below the ocean surface in the Weddell Sea. Sketched on top is the general two-dimensional circulation in the area. The WOCE transect SR4 is marked in mint, and different water masses are distinguished by colors. b Typical section from the Antarctic continent to the transect SR4, with general features of the overturning circulation sketched in black. Highlighted in blue are surface water mass transformations by buoyancy fluxes, and carbon fluxes are marked in green. CDW: Circumpolar Deep Water, WDW: Warm Deep Water, WSDW: Weddell Sea Deep Water, WSBW: Weddell Sea Bottom Water, DSW: Dense Shelf Water, POC: particulate organic carbon.

$(\operatorname{sim} A)$ with a control simulation in a constant climate $(\operatorname{sim} B)$ suggests a reduction in deep-ocean carbon transfer in the southern Weddell Sea towards the end of the $21^{\text {st }}$ century. We show that this can mainly be attributed to changes in water mass properties and water mass transformations on the southern continental shelf, which result in a reduced connectivity between the upper and the deep ocean, thereby diminishing the carbon transfer to the abyss with newly formed dense waters.

\section{Results}

Deep-ocean carbon inventory and air-sea $\mathrm{CO}_{2}$ exchange over the $21^{\text {st }}$ century. In the southern Weddell Sea south of the WOCE transect SR4, the total carbon inventory in the deep ocean below $2000 \mathrm{~m}$ increases by $0.75 \mathrm{Pg} \mathrm{C}$ between the years 1980 and 2100 under the high-emission SSP5-8.5 scenario ( $\operatorname{simA}$; Fig. 22a), which corresponds to $14 \%$ of the increase in the whole water column in this area (compare to upper-ocean carbon inventory in Supplementary Fig. 1). However, the accumulation in the deep ocean is not steady throughout the $21^{\text {st }}$ century. While the deep-ocean accumulation rate of carbon amounts to $3.7{\mathrm{Tg} \mathrm{C} \mathrm{yr}^{-1}}^{-1}$ in the 1990s, it increases to $14.7 \mathrm{Tg} \mathrm{C} \mathrm{yr}^{-1}$ in the $2080 \mathrm{~s}$, before abruptly declining to $1.5 \mathrm{Tg} \mathrm{C} \mathrm{yr}^{-1}$ in the 2090s (grey bars in Fig. 2p). Over much of the $21^{\text {st }}$ century, the deep-ocean carbon inventory also increases in the control simulation with a constant atmospheric $\mathrm{CO}_{2}$ concentration and without climate-change forcing ( $\operatorname{simB}$; Fig. 2a $)$, demonstrating that the deep ocean of the southern Weddell Sea is not fully equilibrated with the constant atmospheric $\mathrm{CO}_{2}$ concentration $(313 \mathrm{ppm})$ in this experiment, as expected from the chosen spin-up procedure (see Methods). Yet, the total increase by the year 2100 is small in $\operatorname{sim} B(+0.27 \mathrm{Pg} \mathrm{C})$ in comparison to $\operatorname{sim} A$ (Fig. 2a), illustrating that the increase in $\operatorname{sim} A$ is mostly attributable to the high $\mathrm{CO}_{2}$ and climate-change forcing scenario. Further, as we will show in the following, the mechanisms causing the changes in the deep-ocean carbon inventory in $\operatorname{sim} A$ are robust, as corresponding changes in $\operatorname{sim} B$ are much smaller or even opposite in sign. Any change in the deep-ocean accumulation rate of carbon can be 
a

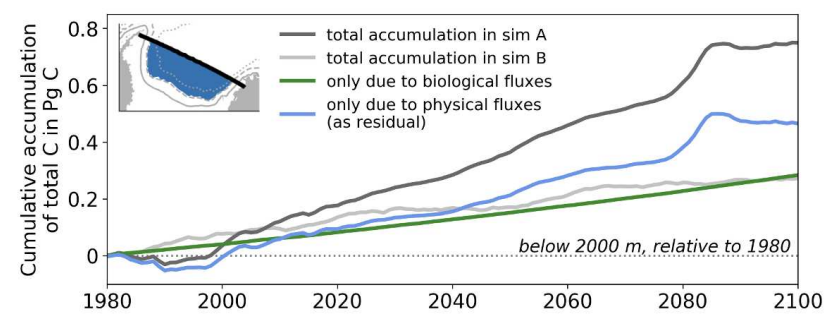

c

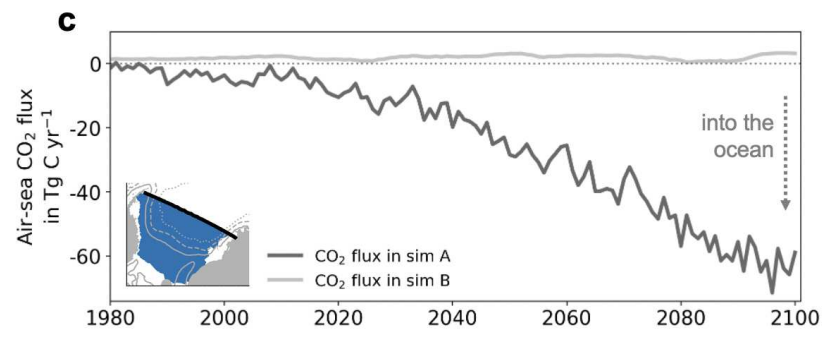

b

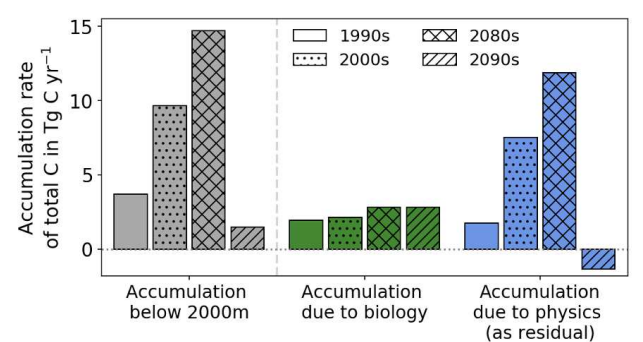

d

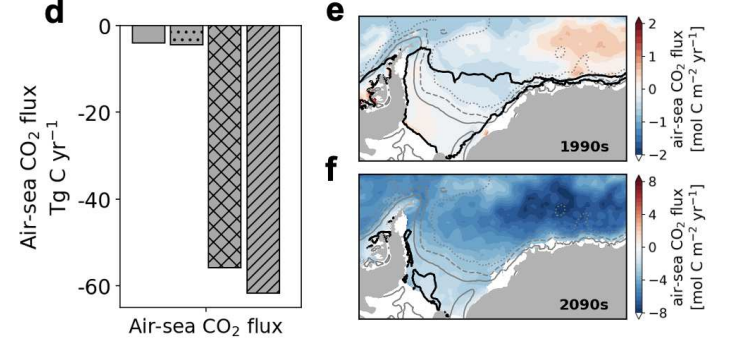

Figure 2: Deep-ocean carbon inventory and air-sea $\mathrm{CO}_{2}$ exchange over the $21^{\text {st }}$ century. a Cumulative carbon accumulation in Pg C below $2000 \mathrm{~m}$ in the southern Weddell Sea south of the WOCE transect SR4 (see blue area in inlet) in the model simulation $\operatorname{simA}$ (dark grey; historical + SSP5-8.5 scenario) and the control simulation $\operatorname{sim} B$ (light grey). The contribution of biological and physical fluxes (calculated as residual) in $\operatorname{sim} A$ are shown in green and blue, respectively. Biological fluxes are dominated by sinking particle fluxes (Supplementary Fig. 2). b Average annual total carbon accumulation rate (grey) and the contribution of biological (green) and physical (blue) fluxes in Tg C yr ${ }^{-1}$ for the 1990s, 2000s, 2080s, and 2090s, as indicated by the hatching of the bars. c Annually integrated air-sea $\mathrm{CO}_{2}$ flux in $\mathrm{Tg} \mathrm{C} \mathrm{yr}^{-1}$ in the southern Weddell Sea south of the transect SR4 (see blue area in inlet) in $\operatorname{sim} A$ (dark grey) and $\operatorname{sim} B$ (light grey). d Air-sea $\mathrm{CO}_{2}$ flux in $\operatorname{sim} A$ averaged over selected decades (see panel $\mathbf{b}$ for legend). e,f Air-sea $\mathrm{CO}_{2}$ flux in $\mathrm{mol} \mathrm{m}^{-2} \mathrm{yr}^{-1}$ in the Weddell Sea in the e 1990s and $\mathbf{f} 2090$ s. Isolines of $15 \%$ sea-ice cover in February in the respective decade are indicated by the black contours. Grey contours show the $700 \mathrm{~m}$ (solid), $2000 \mathrm{~m}$ (dashed), and $3500 \mathrm{~m}$ (dotted) isobaths. For panels c-f, a negative $\mathrm{CO}_{2}$ flux denotes a flux into the ocean.

caused by changes in the downward transfer of carbon via biological fluxes (i.e., sinking particles and carbon fluxes at the sediment-water column-interface), changes in the physical transport of carbon, or changes in the upper-ocean carbon inventory due to changes in air-sea $\mathrm{CO}_{2}$ exchange. While the southern Weddell Sea remains a small source of $\mathrm{CO}_{2}$ to the atmosphere until the year 2100 in the control simulation $\left(\sim 2 \mathrm{Tg} \mathrm{C} \mathrm{yr}^{-1}\right.$, see Fig. 22), oceanic $\mathrm{CO}_{2}$ uptake in this area in $\operatorname{sim} A$ increases throughout the $21^{\text {st }}$ century, amounting to $62 \mathrm{Tg} \mathrm{C} \mathrm{yr}^{-1}$ in 2100 (Fig. $2 \mathrm{~F}$-f). As a consequence, also the upper ocean carbon inventory increases steadily (Supplementary Fig. 1).

At the same time, the deep-ocean carbon accumulation due to biological fluxes increases from $1.9{\mathrm{Tg} \mathrm{C} \mathrm{yr}^{-1}}^{-1}$ in the 1990s to $2.8 \mathrm{Tg} \mathrm{C} \mathrm{yr}^{-1}$ in the 2090s (green bars in Fig. 2b). This increase is largely due to an enhanced sinking flux of particulate organic carbon (POC) with only a marginal contribution from sedimentary carbon release (Supplementary Fig. 2). The increased POC flux is the direct consequence of a $56 \%$ increase in biological productivity in the upper ocean south of SR4 (not shown), in response to warming and higher light availability due to the shrinking summer sea-ice cover by 2100 (Fig. 22 \& f). Altogether, the steady increases in oceanic $\mathrm{CO}_{2}$ uptake, in the upper-ocean carbon inventory, and in the downward carbon transfer with the biological pump imply that these fluxes cannot explain the simulated decline in deep-ocean carbon accumulation in the 2090s. Instead, this decline is dominated by changes in the physical fluxes of carbon in the model. While the deep-ocean carbon accumulation due to physical transport increases from $1.8{\mathrm{Tg} \mathrm{C} \mathrm{yr}^{-1}}^{-1}$ in the 1990s to $11.9 \mathrm{Tg} \mathrm{C} \mathrm{yr}^{-1}$ in the 2080s, it dwindles and even changes sign in the 2090s, when all physical fluxes combined constitute a net loss of carbon from the deep ocean (1.3 $\mathrm{Tg} \mathrm{C} \mathrm{yr}^{-1}$; blue bars in Fig. 2b). Taken together, by the end of the $21^{\text {st }}$ century, the deep-ocean carbon inventory continues to increase - albeit at a much smaller rate compared to the previous decades - only due to the increased biological fluxes which outweigh the physically-driven decline.

Disentangling the physical flux components contributing to deep-ocean carbon accumulation. In 
a

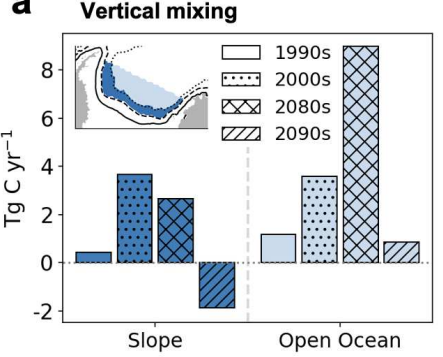

b

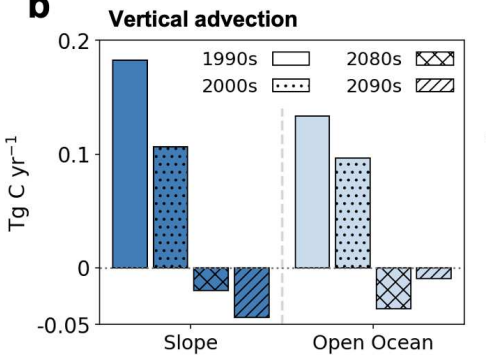

C Lateral advection

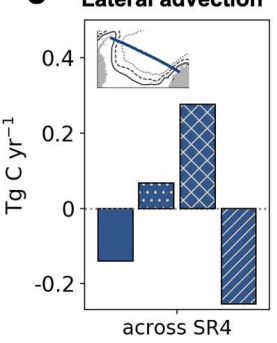

d Other components

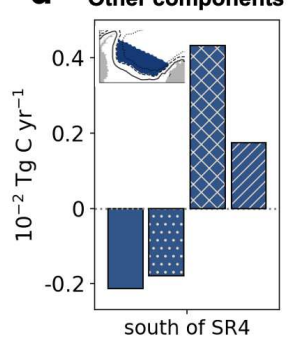

Figure 3: Divergence of physical flux components contributing to changes in the deep-ocean carbon inventory in the southern Weddell Sea. Positive fluxes denote an increase in the deep-ocean carbon inventory in the volume of interest due to the respective flux component. Changes in the total carbon inventory south of WOCE transect SR4 and below $2000 \mathrm{~m}$ in the model simulation $\operatorname{simA}$ (grey; historical + SSP5-8.5 scenario) due to a vertical mixing across $2000 \mathrm{~m}$, b vertical advection across $2000 \mathrm{~m}$, c lateral advection across the transect SR4, and $\mathbf{d}$ the sum of all other flux components, e.g., from the eddy parametrization. All fluxes are

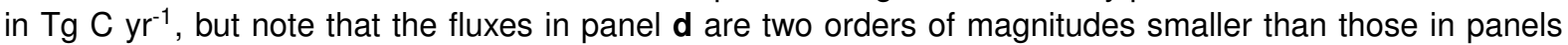
a-c. All fluxes are shown for the 1990s, 2000s, 2080s, and 2090s, as indicated by the differences in hatching. Vertical fluxes in panels $\mathbf{a} \mathbf{\&} \mathbf{b}$ are shown for the continental slope (dark blue) and the open ocean (light blue), which are separated at the $3500 \mathrm{~m}$ isobath (see inlet in panel a).

general, changes in the deep-ocean carbon accumulation rate due to physical transport can be due to lateral or vertical fluxes via advection or mixing. For the deep-ocean carbon budget considered here, the divergence of vertical fluxes typically dominates over the contribution by lateral fluxes (Fig. 3), as gradients in total carbon concentrations in the vertical exceed those in the lateral (Supplementary Fig. 3). In our model, vertical mixing is the dominant flux component in the southern Weddell Sea (Fig. 3a), with all others being at least one order of magnitude smaller (e.g., vertical and lateral advection; Fig. 3p-d). Consequently, vertical mixing as a signature of convection accounts for $>90 \%$ of the total physically-driven carbon accumulation throughout much of the $20^{\text {th }}$ and $21^{\text {st }}$ century, and this flux component alone can explain most of the simulated evolution in deep-ocean carbon accumulation (compare Fig. $3 \mathrm{a}$ to blue bars in Fig 20). While the slope region between the $2000 \mathrm{~m}$ and $3500 \mathrm{~m}$ isobaths contributes up to $50 \%$ to the downward transfer of carbon in the $2000 \mathrm{~s}$, the enhanced downward transfer in the 2080s can largely be attributed to enhanced downward mixing in the open ocean ( $\sim 8 \mathrm{Tg} \mathrm{C} \mathrm{yr}^{-1}$; Fig. 3a and Supplementary Fig. 4), with only minor contributions from other components (Fig. $3 \mathrm{~b}-\mathrm{d}$ and Supplementary Fig. 5). The enhanced open-ocean downward mixing of carbon in the 2080s is the result of the downward mixing of relatively recently ventilated and thus carbon-enriched dense waters originating from regions upstream of the southern Weddell Sea (Supplementary Fig. 6 and Supplementary Section 1). In the 2090s, a much reduced open-ocean downward mixing $\left(<1 \mathrm{Tg} \mathrm{C} \mathrm{yr}^{-1}\right)$ is outweighed by upward mixing along the slope and the two advective flux components, which all act to reduce the deep-ocean carbon inventory and thus explain the net loss of carbon from the deep ocean by physical fluxes in this decade (blue bars in Fig. 2b). In this context, the increasingly upwards-directed advective flux is in line with enhanced upwelling of deep waters resulting from the intensified upper ocean gyre circulation at the end of the $21^{\text {st }}$ century (see barotropic stream function in Supplementary Fig. 5 and references ${ }^{960}$ ). Overall, the dominance of vertical physical fluxes in controlling the variability in carbon transfer to depth - in particular the attenuated transfer in the 2090s - implies that deep-ocean carbon accumulation rates are sensitive to physical processes in the overlying water column and upstream on the Weddell Sea continental shelves.

Indeed, bottom waters descending the continental slope in $\operatorname{sim} A$ are less well connected to the upper ocean towards the end of the $21^{\text {st }}$ century than they were before (Fig. $4 \mathrm{a} \& \mathrm{c}$ ), which is explained in the following. To assess this connectivity, we use an age tracer, which tracks any water parcel's last contact with the atmosphere-ocean, sea ice-ocean, or ice shelf-ocean interface as it mixes with surrounding waters in the ocean interior in our model simulations (see Methods). Everywhere on the continental shelf south of the $700 \mathrm{~m}$ isobath (solid black line in Fig. $4 \mathrm{a}$ ), bottom waters are well ventilated in the 1990 s, when $>80 \%$ of the bottom waters have been in touch with one of these interfaces since the start of the simulation (purple colors in Fig. (4a). In comparison, bottom waters south of SR4 are far less well ventilated in the same decade both on the continental slope $(50 \%)$ and in the open ocean $(<30 \%)$, i.e., north of the $3500 \mathrm{~m}$ isobath (green colors north of the dotted black line in Fig. 4a). This is further illustrated by the far better mixed water column on the Weddell Sea continental shelf compared to in the open ocean (Supplementary Fig. 7), implying longer 

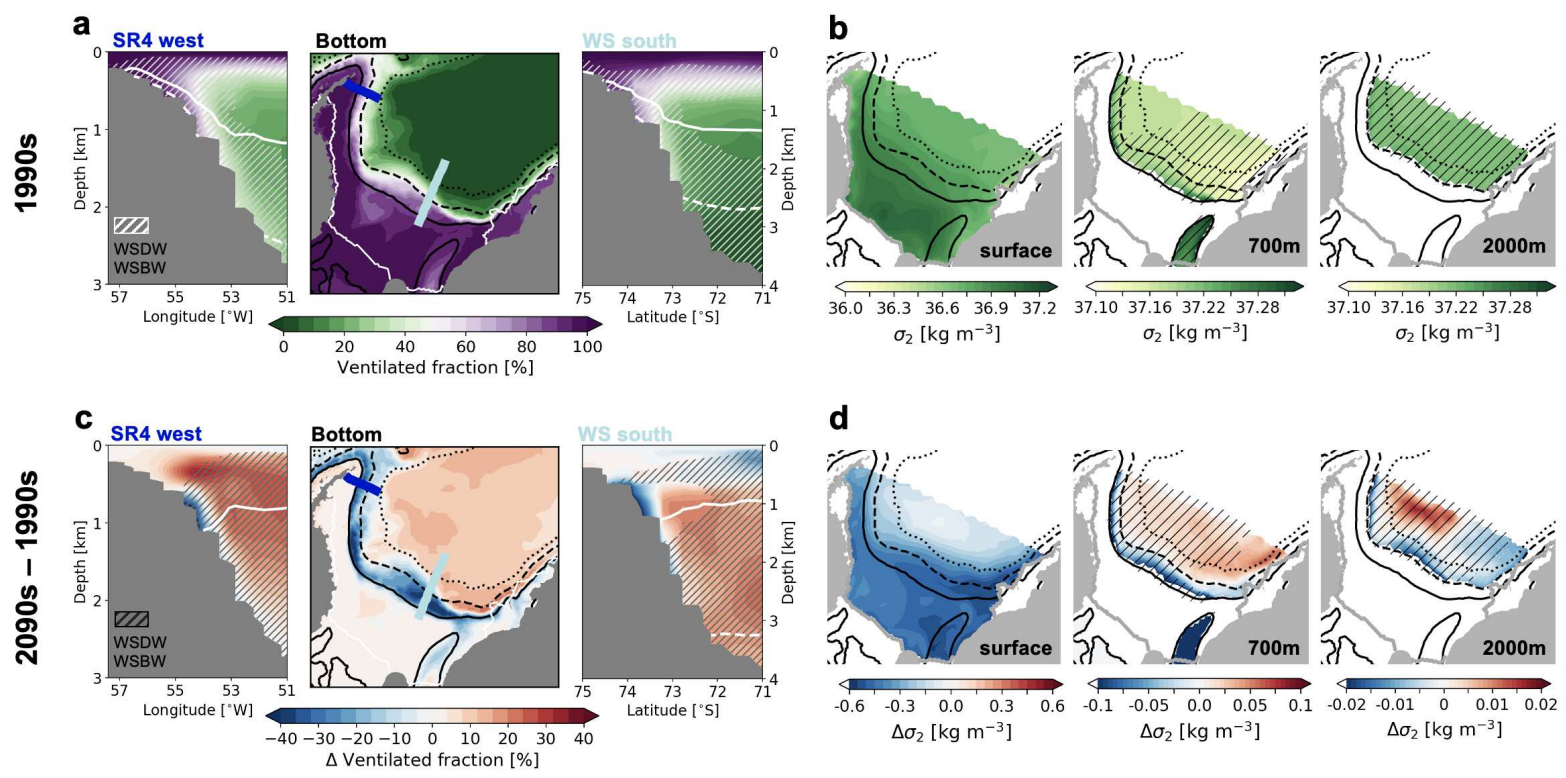

Figure 4: Bottom water ventilation and density distribution over the $21^{\text {st }}$ century. a Age-tracer-based fraction of water that is ventilated at the bottom (middle) and across the continental slope in the western (SR4 west; left) and southern Weddell Sea (WS south; right) in the 1990s. The positions of the transects are indicated in the map as the dark blue (SR4 west) and the light blue line (WS south), respectively. b Distribution of potential density anomalies $\left(\sigma_{2}\right.$ in $\mathrm{kg} \mathrm{m}^{-3}$, i.e., potential density referenced to $2000 \mathrm{dbar}$ minus $1000 \mathrm{~kg} \mathrm{~m}^{-3}$ ) at the surface, $700 \mathrm{~m}$, and $2000 \mathrm{~m}$ in the 1990s. Note the different scales. c,d Same as panels a,b, but for the change in $\mathbf{c}$ the ventilated fraction and $\mathbf{d} \sigma_{2}$ between the 2090s and the 1990s. In the transects in panels a,c, $\sigma_{2}$ isolines for the a 1990s and $\mathbf{c} 2090 \mathrm{~s}$ are shown as the solid $\left(37.2 \mathrm{~kg} \mathrm{~m}^{-3}\right)$ and dashed $\left(37.25 \mathrm{~kg} \mathrm{~m}^{-3}\right)$ white contour, respectively. In the maps in panels b,d, black contours show the $700 \mathrm{~m}$ (solid), $2000 \mathrm{~m}$ (dashed), and $3500 \mathrm{~m}$ (dotted) isobaths. In all panels, hatching denotes the presence of Weddell Sea Deep Water and Weddell Sea Bottom Water in the a,b 1990s and c,d 2090s, defined in the model as waters with a potential temperature $<-0.2^{\circ} \mathrm{C}$ and a practical salinity $>34.55$.

time scales associated with bottom water ventilation in the open ocean than on the continental shelf. In the 2090s, the ventilation rate remains largely unchanged on the continental shelf, but declines profoundly along the slope (locally by more than 40\%, Fig. 4b), demonstrating a reduced connectivity between the continental shelf and the deep ocean by the year 2100 . Changes in the density distribution support this finding: While the densities at $700 \mathrm{~m}$ and $2000 \mathrm{~m}$ in the open ocean mostly increase in response to the intensification of the gyre circulation and the corresponding increase in upwelling over the $21^{\text {st }}$ century (Supplementary Fig. 5), densities close to the continental slope decline by up to $0.2 \mathrm{~kg} \mathrm{~m}^{-3}$ and $0.033 \mathrm{~kg} \mathrm{~m}^{-3}$ at $700 \mathrm{~m}$ and $2000 \mathrm{~m}$, respectively (potential density referenced to $2000 \mathrm{dbar}$; Fig. $4 \mathrm{~d}$ ). In fact, while isopycnals of high density, i.e., $\sigma_{2}>37.2 \mathrm{~kg} \mathrm{~m}^{-3}$, are connected to the continental shelf sea in the 1990s (white isolines in Fig. 4 4 ), providing a pathway of WSDW and WSBW into the abyss, this connectivity is absent by 2100 (Fig. 4c). As a consequence, this implies major changes in water mass properties and transformations on the southern Weddell Sea continental shelves, where new dense waters are typically formed.

Changes in water mass properties and dense water formation on the Weddell Sea continental shelf. Under the high-emission SSP5-8.5 scenario, water mass properties are projected to change throughout the water column on the southern Weddell Sea continental shelf (Fig. 5). While the decline in density is largest at the surface $\left(\Delta \sigma_{2}<-0.5 \mathrm{~kg} \mathrm{~m}^{-3}\right.$ at the continental shelf break along the $700 \mathrm{~m}$ isobath; Fig. $5 \mathrm{e}$ \& $\mathrm{f}$ and Fig. $4 \mathrm{~d}$ ), the average decline in bottom density on the shelf is still significant, amounting to $0.28 \mathrm{~kg} \mathrm{~m}^{-3}$ (Fig. $5 \mathrm{a}$ ). This decline is due to a combination of a pronounced freshening $(-0.31$ in salinity; Fig. $5 \mathrm{~b})$ and warming $\left(+0.35^{\circ} \mathrm{C}\right.$; Fig. 5c) of bottom waters by the end of the $21^{\text {st }}$ century. Concurrently, the total heat content on the shelf increases by $66 \%$ (Fig. $5 \mathrm{~d}$ ), reflecting both an increased presence of WDW on the shelf and the reduction of heat loss to the atmosphere. Most of these simulated changes can be attributed to the climate-change forcing scenario, as trends in these properties in the control experiment $\operatorname{sim} B$ are much smaller or even opposite in sign (light grey bars in Fig. $5 \mathrm{a}-\mathrm{d}$ ). As a result, keeping the definition of the water masses unchanged, less DSW has temperature $\left(<-0.2^{\circ} \mathrm{C}\right)$ and salinity $(>34.55$; see also Methods) properties of WSDW or WSBW in the 2090s as compared to in the 1990s. While most waters at the continental shelf break fulfill these criteria in 

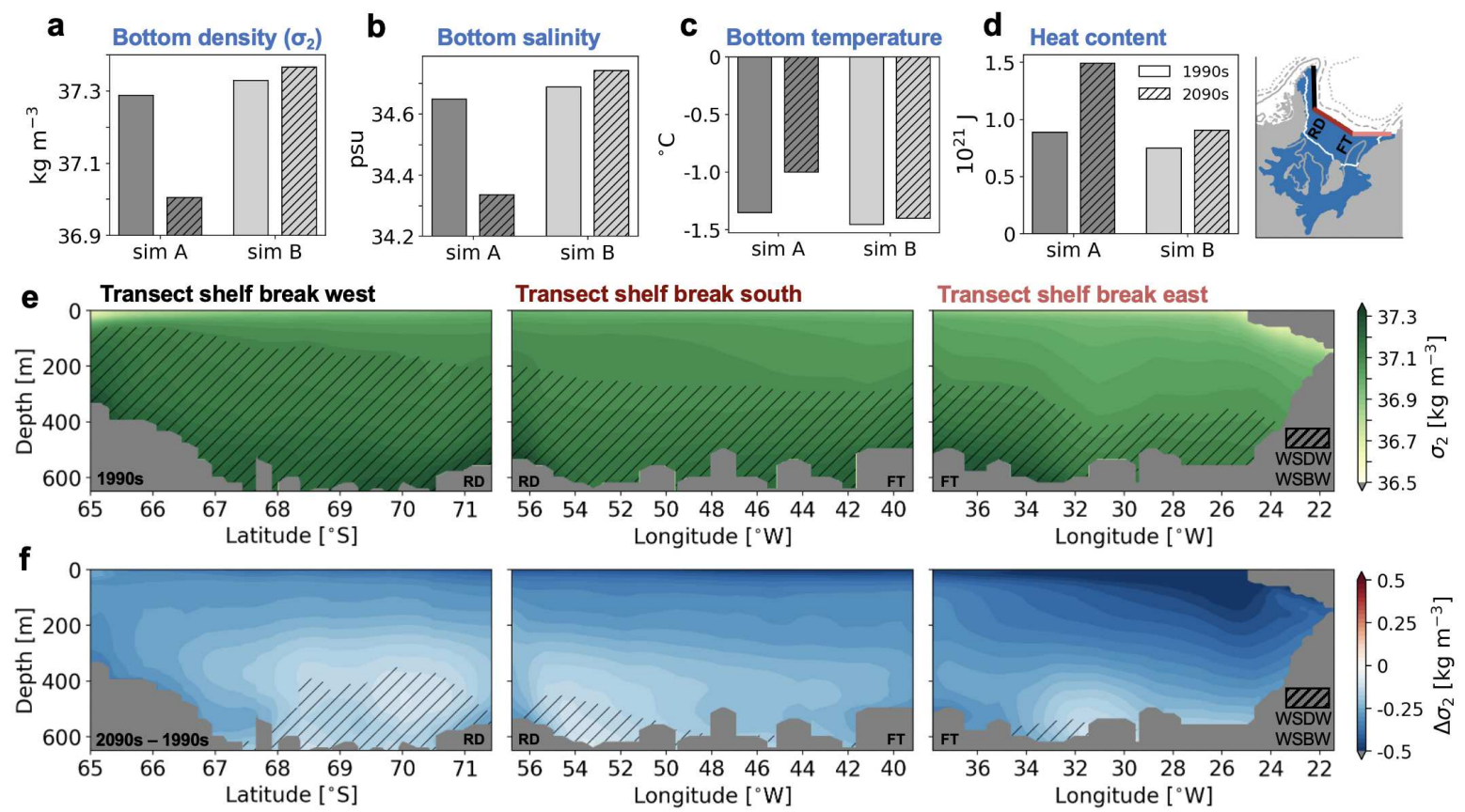

Figure 5: Changes in water mass properties on the Weddell Sea continental shelf. a Bottom potential density anomaly referenced to $2000 \mathrm{dbar}\left(\sigma_{2}\right)$ in $\mathrm{kg} \mathrm{m}^{-3}$ on the shelf (blue area in the map) in the 1990s (plain bar) and 2090s (hatched bar) in the experiment $\operatorname{sim} A$ (dark grey; historical + SSP5-8.5 scenario) and in the control simulation $\operatorname{sim} B$ (light grey). $\mathbf{b}$-d Same as panel $\mathbf{a}$, but for $\mathbf{b}$ bottom salinity, $\mathbf{c}$ bottom potential temperature in ${ }^{\circ} \mathrm{C}$, and $\mathbf{d}$ total heat content in $10^{21} \mathrm{~J}$. e Distribution of potential density anomalies $\left(\sigma_{2}\right.$ in $\mathrm{kg} \mathrm{m}^{-3}$, i.e., potential density referenced to $2000 \mathrm{dbar}$ minus $1000 \mathrm{~kg} \mathrm{~m}^{-3}$ ) at a transect along the continental shelf break (see black line in map) in the 1990s. f Same as panel e, but for the change in $\sigma_{2}$ between the 2090s and the 1990s. Hatching in panels $\mathbf{e} \& \mathbf{f}$ denotes the presence of Weddell Sea Deep Water and Weddell Sea Bottom Water in the $\mathbf{e} 1990 \mathrm{~s}$ and $\mathbf{f} 2090 \mathrm{~s}$, defined in the model as waters with a potential temperature $<-0.2^{\circ} \mathrm{C}$ and a practical salinity $>34.55$. The approximate positions of the Ronne Depression (RD) and the Filchner Trough (FT) are indicated.

the 1990 s ( $61 \%$ of the total ocean area; Fig. 5 e), the area covered by these dense waters has shrunk to only $13 \%$ by the year 2100 (Fig. [5), thereby ultimately affecting the water mass properties of newly formed AABW in the southern Weddell Sea. In fact, the reduction in bottom density at the shelf break is most pronounced where shelf water is exported to the abyss, namely in the Filchner Trough and in the northwestern Weddell Sea $\left(-0.3 \mathrm{~kg} \mathrm{~m}^{-3}\right.$; Fig. 5), and is smallest in the Ronne Depression $\left(-0.1 \mathrm{~kg} \mathrm{~m}^{-3}\right)$, where most newly formed dense waters enter the ice-shelf cavity and undergo freshening before leaving the shelf via the Filchner Trough (see Fig. 1 and reference $e^{19}$ ). Therefore, the overall lower density of DSW at the end of the $21^{\text {st }}$ century directly affects the transfer of these dense waters from the continental shelf to the deep ocean (see white isolines in Fig. $4 \mathrm{a}$ ) and suggests significant changes in water mass transformation on the continental shelf.

The densification of waters in the southern Weddell Sea can be assessed in the water mass transformation (WMT) framework, which relates surface density distributions to buoyancy fluxes at the atmosphereocean, sea ice-ocean, or ice shelf-ocean interface and from which areas and formation rates of downwelling dense water masses can be derived (see Methods and references ${ }^{40161} \sqrt{64}$ ). Total WMT rates are largely positive on the Weddell Sea continental shelf (black lines in Fig. 6a), indicating an overall densification of surface waters by buoyancy fluxes in this area, which is in agreement with observations ${ }^{17}$. In the 1990s, the formation of dense waters on the southern Weddell Sea continental shelf amounts to $5.4 \mathrm{~Sv}$ in $\operatorname{simA}$ (peak in solid black line in Fig. 6a), fairly close to the recent observation-based estimate of $4.5 \pm 0.3 \mathrm{~S} \sqrt{16}$. In this region, it can mostly be attributed to net sea-ice growth (blue line in Fig. 6a), with only small modifications by ice-shelf freshwater fluxes (mint line in Fig. 6a), which counter the densification of waters by sea-ice formation and without which dense-water formation in the area would be $\sim 0.6 \mathrm{~Sv}$ higher. In response to the environmental change over the course of the $21^{\text {st }}$ century, sea-ice formation is projected to be $16 \%$ lower and ice-shelf basal melting $79 \%$ higher in the 2090s than in the 1990s (Fig. 6r \& d). Southern Weddell Sea dense water 
a

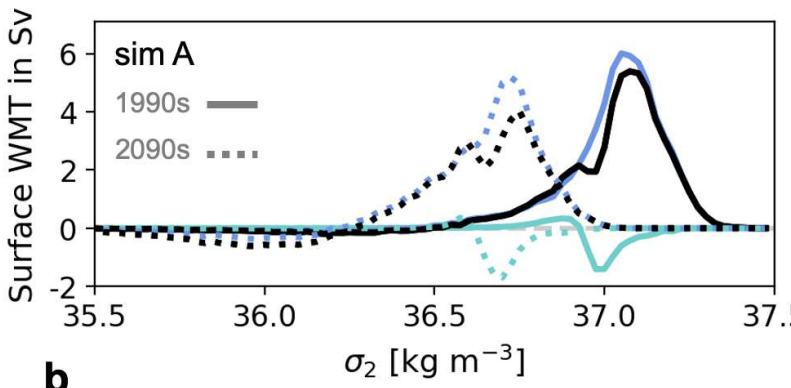

$>$

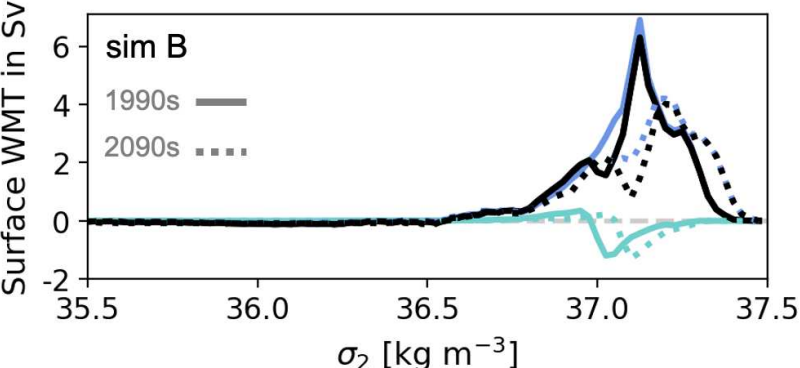

C
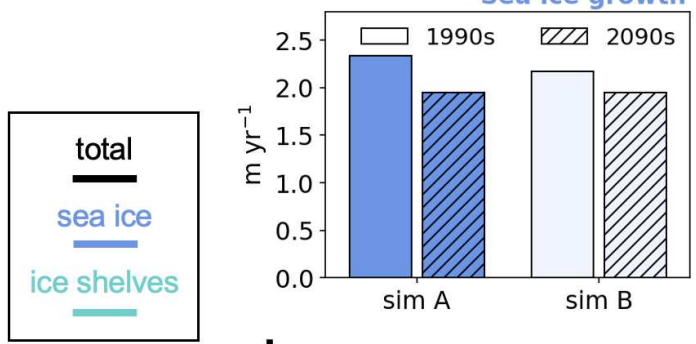

d

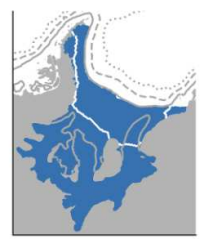

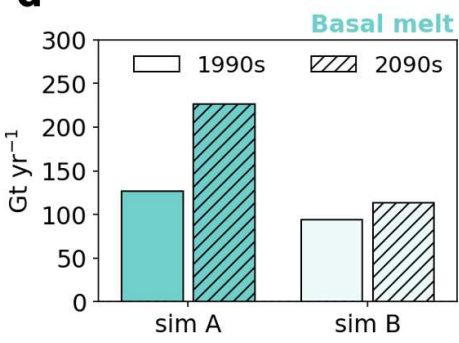

Figure 6: Water mass transformations due to surface buoyancy fluxes on the southern Weddell Sea continental shelf. a, b Surface water mass transformation rates (WMT) in Sverdrup (Sv; $1 \mathrm{~Sv}$ is $1.10^{6} \mathrm{~m}^{3} \mathrm{~s}^{-1}$ ) as a function of the density anomaly $\left(\sigma_{2}\right.$; potential density referenced to $\left.2000 \mathrm{dbar} ; \mathrm{kg} \mathrm{m}^{-3}\right)$ due to the total buoyancy flux (black) and due to buoyancy fluxes from sea ice (blue) and ice shelves (mint) on the southern Weddell Sea continental shelf (see blue area in map) in the 1990s (solid) and 2090s (dotted) from a $\operatorname{sim} A$ (historical + SSP5-8.5 scenario) and $\mathbf{b}$ the control simulation simB. Positive transformations denote a densification of surface waters due to buoyancy fluxes. Transformations due to heat fluxes and freshwater fluxes from evaporation minus precipitation are an order of magnitude smaller than those shown here (see Supplementary Fig. 8). c Sea-ice growth in $\mathrm{m} \mathrm{yr}^{-1}$ and $\mathbf{d}$ ice-shelf basal melt rates in $\mathrm{Gt}_{\mathrm{yr}} \mathrm{H}^{-1}$ The bars in panels $\mathbf{c}$ \& d denote averages for the 1990s (plain) and the 2090s (hatched) in $\operatorname{sim} A$ (darker colors) and $\operatorname{sim} B$ (lighter colors), respectively.

formation in the 2090s in simA is $1.4 \mathrm{~Sv}$ lower than in the preceding century (Fig. 6a), but this decline has to at least partially be attributed to model drift, as dense water formation in the control experiment $\operatorname{sim} B$ shows a similar decline in magnitude in the area of interest (Fig. 60). In contrast, the simulated shift of dense water formation to lighter density classes in $\operatorname{sim} A$ towards the end of the $21^{\text {st }}$ century can clearly be attributed to climate change (Fig. $6 \mathrm{a} \& \mathrm{~b}$ ). The reduced sea-ice formation and increased freshwater discharge from ice shelves in the southern Weddell Sea are the dominant reasons for this shift, but property changes in the source waters upstream also play a role. Waters on the eastern Weddell Sea continental shelf experience pronounced freshening and particularly warming by the year $2100\left(-0.026\right.$ in salinity and $+0.64{ }^{\circ} \mathrm{C}$, respectively; see Supplementary Fig. 9), and the $40 \%$ lower sea-ice formation and 8-fold higher basal melt rates result in much lighter waters flowing into the southern Weddell Sea in the 2090s than in the 1990s (Supplementary Fig. 10). Thereby, these lighter source waters amplify the shift towards lighter densities of newly formed dense waters in the southern Weddell Sea, where these become too light in our model experiments to sustain contemporary rates of carbon transfer to the deep ocean at the end of the $21^{\text {st }}$ century.

\section{Discussion}

Using a model setup that, for the first time, includes both ice-shelf cavities and a description of the ocean carbon cycle, our results quantify the role of both physical and biological processes in deep-ocean carbon accumulation in the southern Weddell Sea. Over much of the $21^{\text {st }}$ century, the carbon transfer to the abyss due to physical processes is up to four times higher than due to biological processes in the high-emission scenario, until the physically-driven transfer abruptly declines in the 2090s (Fig. 2). The simulated decline in dense-water transfer to the deep ocean in response to enhanced stratification is generally in line with previous modelling experiments ${ }^{7}$. However, in contrast to some Earth System Models ${ }^{7}$, our model does not 

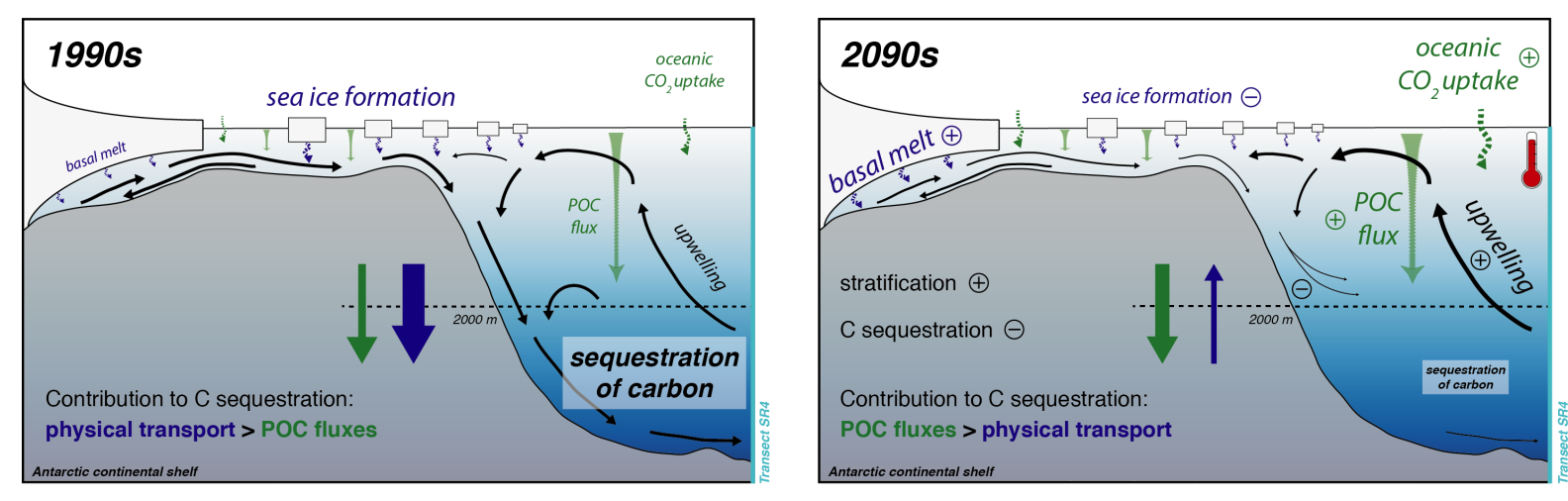

Figure 7: Sketch illustrating the simulated changes over the $21^{\text {st }}$ century in the high-emission scenario. Compared to the 1990s, deep-ocean carbon sequestration in the southern Weddell Sea is reduced by $60 \%$, which is largely attributed to a reduction in the physical transport of carbon to the abyss. In particular, sea-ice formation is reduced by $16 \%$, and ice-shelf basal melt increases by $79 \%$, which both act to increase the stratification of the water column. Despite the 10 -fold increase in oceanic $\mathrm{CO}_{2}$ uptake and a $47 \%$ increase in sinking fluxes of biotic particles (POC), the decline in physically-driven downward transport dominates, as newly formed lighter dense waters on the continental shelf are transferred to shallower depths in the 2090s, reducing carbon accumulation in the deep ocean. In the sketch, font sizes and arrow thicknesses in the 2090 s are scaled to approximately represent the magnitude of the simulated changes.

suggest a complete shutdown of dense water formation by the end of the $21^{\text {st }}$ century, but a less efficient transfer of newly formed dense waters from the Weddell Sea continental shelves to the abyss (Fig. 7). This discrepancy can be understood by looking at the mechanisms involved in dense water formation in the different model experiments. Typically, the slowdown or shutdown of bottom water renewal simulated in Earth System Models occurs due to a reduction in (unrealistic) open-ocean deep convection in areas north of the transect considered in this study (Fig. $11^{7}$. Instead, in our model experiments, pronounced freshening and warming of waters on the southern Weddell Sea continental shelf are largely responsible for this change. As the bottom water density decline is largest along pathways of dense water export from the southern shelves to the abyss (Filchner Trough and northwestern Weddell Sea shelf; see Fig. 11\& Fig. 5), bottom waters in the open-ocean southern Weddell Sea are effectively cut off from renewal with waters descending the continental slope, as the newly formed lighter dense waters end up at shallower depths. Although the downstream effects may be similar, namely less carbon sequestration in the high-latitude Southern Ocean, bottom water renewal is known to predominantly occur along the continental margins ${ }^{13} \cdot 16$. Thus, our model experiments display a more realistic representation of the mechanisms involved in dense water formation and transfer to the deep ocean, which is indispensable when aiming to anticipate their response to the on-going environmental change.

In comparison to earlier modeling studies projecting an up to 15 -fold increase in ice-shelf basal melt rates $^{41-44}$, the projected $79 \%$ increase in Weddell Sea ice-shelf basal melt by 2100 in our model is much more moderate. In fact, our projected increase is much closer to the values recently reported by Naughten et al $.45[46$, who - like in this study - used atmospheric output from state-of-the-art climate projections to force their ocean model experiments. In their studies, ice-shelf basal melt rates in the Weddell Sea are projected to increase by $99 \%$ in the high-emission RCP8.5 scenario ${ }^{45}$, and much higher atmospheric $\mathrm{CO}_{2}$ levels than those considered in our study are required to induce an up to five-fold increase in basal meli $\frac{46}{}$. Acknowledging that we have only used output from a single climate model here, our results are nevertheless in line with Naughten et al $145 / 46$, suggesting that earlier studies ${ }^{41+44}$ using an older forcing scenario may have been too prone to WDW intrusions onto the continental shelf and hence overestimated the future basal melt rate increase in the area (see also discussion in reference ${ }^{46}$ ). While a cold bias in WDW in our model (Supplementary Fig. $11 \& 12$ ) might imply that our experiments underestimate the response of basal melt rates to the climate-change forcing, the simulated present-day basal melt rates in the Weddell Sea (127 Gt yr ${ }^{-1}$

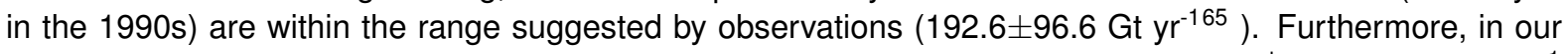
model experiment, the increase in basal melt rates accelerates towards the end of the $21^{\text {st }}$ century $\left(143 \mathrm{Gt}^{-1}\right.$ in the 2070s, $168 \mathrm{Gt} \mathrm{yr}^{-1}$ in the 2080s, $226 \mathrm{Gt} \mathrm{yr}^{-1}$ in the 2090s), suggesting that basal melt rates would likely continue to rise beyond 2100 , further freshening the shelf and subsequently reducing the density of newly formed dense waters, possibly resulting in a continued low transfer of carbon to the abyss of the southern Weddell Sea. 
As a result of the simulated changes in the physical environment (e.g., in sea-ice cover), the transfer of carbon to the abyss with sinking biotic particles increases over the $21^{\text {st }}$ century (Fig. 7). While the present-day biological pump adjacent to the southern Weddell Sea continental shelves is thought to be efficient in transferring biotic particles to the deep ocear $\sqrt{666}$, several studies have suggested rather shallow remineralization of those particles in the central Weddell Sea ${ }^{9 / 51 / 67}$. In particular, MacGilchrist et al! ${ }^{51}$ have recently shown that biological fluxes in the Weddell Sea significantly contribute to carbon accumulation above $2000 \mathrm{~m}$ (CDW layer), but to a lesser extent to water masses below that, which is in line with our findings for the present time. Yet, by the year 2100, the carbon inventory of the southern Weddell Sea below $2000 \mathrm{~m}$ changes from being physically-controlled to being biologically-controlled in our model experiment, which also holds true for the accumulation below $2500 \mathrm{~m}$ and $3000 \mathrm{~m}$, respectively (Supplementary Fig. 13). This regime shift is dominated by the decrease in the physically-driven downward carbon transfer (due to the increased stability of the water column), which outweighs the increase in the biologically-driven transfer (due to more primary productivity and sinking particle fluxes) and which results in deep-ocean carbon accumulation rates in the 2090s amounting to only $40 \%$ of those simulated in the 1990 s. However, we acknowledge that we might underestimate the future role of biotic particle fluxes in our model experiment. At high latitudes, phytoplankton growth is generally limited by the availability of micronutrients, such as iron, and the rather short growing season at these latitudes ${ }^{968}$. While the latter will likely be prolonged by 2100 as a result of the shrinking sea ice cover (Fig. 2f), iron supplied by meltwater from sea ice or icebergs was shown to be a source of iron for high-latitude phytoplanktor ${ }^{69}$, suggesting substantial fertilization as melt rates increase over the $21^{\text {st }}$ century. This nutrient supply mechanism is currently not accounted for in our model, but might augment the biological response to environmental change. Instead, here, the attenuation of deep-ocean carbon accumulation in the southern Weddell Sea is controlled by changes in physical processes, namely the shift in water mass properties and transformations in the upper ocean, which act to reduce the vertical downward transfer of carbon to the abyss with dense waters.

Rates of carbon sequestration - if given relative to the $\mathrm{CO}_{2}$ uptake at the ocean surface - are an indicator of the sequestration efficiency, but the sequestration depth is decisive for the storage permanence, which describes how long the sequestered carbon will ultimately be locked away from the atmosphere. In the Weddell Sea, a high storage permanence on the order of centuries or more is likely if the carbon is transferred to the bottom of the ocean with WSBW along the continental slope 6 [51. In contrast, the storage permanence is likely much shorter if the carbon is only transferred to mid-depths, from where upwelling might bring the freshly sequestered carbon to the surface again within a few years or decades (especially in the central Weddell Sea $\sqrt{6 / 9151}$. Under the high-emission scenario considered in this study, the fraction of the oceanic $\mathrm{CO}_{2}$ uptake sequestered below $2000 \mathrm{~m}$ in the southern Weddell Sea declines from 93\% in the 1990s to only $2 \%$ in the 2090s (Fig. 2). This reduced sequestration efficiency implies that an increasing amount of carbon is stored at mid-depths and in the upper ocean over the $21^{\text {st }}$ century (Supplementary Fig. 1). Indeed, most of the $\mathrm{CO}_{2}$ taken up at the surface in the southern Weddell Sea throughout the $21^{\text {st }}$ century evades long-term sequestration in the deep ocean, with cumulative deep-ocean carbon accumulation until 2100 amounting to $26 \%$ of the total $\mathrm{CO}_{2}$ uptake south of the transect SR4. While it remains unclear how carbon sequestration in the southern Weddell Sea evolves beyond the year 2100 under continuous climate-change forcing and to what extent the attenuation of carbon sequestration rates in this region by 2100 is avoidable under a lower-emission scenario, it is clear that a reduction in deep-ocean carbon accumulation will induce climate feedbacks down the road as a consequence of the reduced storage permanence.

In summary, the evolution of deep-ocean carbon sequestration in the southern Weddell Sea is closely tied to the evolution of buoyancy fluxes from sea ice and ice shelves and hence dense water formation in the area. Therefore, based on our results, the crossing of any critical threshold in high-latitude freshwater discharge, i.e., a tipping point above which newly formed dense waters are so light that they cease to reach the abyss ${ }^{70}$, will likely be associated with a concurrent cessation in carbon sequestration. Additional research will be needed to elucidate whether such a tipping point has already been crossed by the end of our model experiment, or whether this abrupt decline is a non-permanent early warning signal of the imminent crossing of such a tipping point. Furthermore, it remains an open question whether such a tipping point can be avoided under lower emission scenarios. In conclusion, the projected freshening of Weddell Sea shelf waters and the associated reduction in bottom water renewal reduce their capacity to store carbon on centennial and millennial time scales, with consequences for the partitioning of carbon between the ocean and atmosphere and hence climate. 


\section{Methods}

316 Description of FESOM-REcoM. We use the global Finite Element Sea Ice Ocean Model (FESOM) version

$1.4^{54}$ which includes a dynamic-thermodynamic sea-ice mode ${ }^{55}$ and an ice-shelf componen ${ }^{58}$. Ice-shelf geometry and bottom topography are derived from RTopo- $2^{71}$ and prescribed to be constant in our model experiments. Coupled to FESOM is the Regulated Ecosystem Model version 2 (REcoM2) ${ }^{\sqrt{53}}$ [56/57 , which resolves the biogeochemical cycling of carbon, nitrogen, silicon, iron, and oxygen with a total of 28 prognostic tracers. The lower trophic level ecosystem is composed of two phytoplankton groups (silicifying diatoms and a mixed nanophytoplankton group, of which a fraction calcifies) and two zooplankton groups. Stoichiometric ratios are allowed to vary in REcoM2. Organic matter cycling is parametrized with one class of non-sinking dissolved organic matter and two size classes of particulate organic matter, which are remineralized as they sink through the water column. A fraction of the sinking particles reaches the sediment layer in the model, from which they are released back into the water column in dissolved form with fixed remineralization rates ${ }^{53}$. Consequently, any change in the deep-ocean carbon inventory due to biological fluxes is caused by changes in either the sinking particle flux across the depth horizon of interest (2000 $\mathrm{m}$ in this study) or in the release of dissolved inorganic carbon from the sediments, with the former dominating in the southern Weddell Sea (Supplementary Fig. 2). The total carbon inventory as assessed in this study refers to the sum of the following model tracers: dissolved inorganic carbon, dissolved organic carbon, two classes of sinking particulate organic carbon, particulate inorganic calcite, living particulate organic carbon associated with the two phytoplankton and two zooplankton groups, and calcite associated with the nanophytoplankton group.

Model setup, model assessment, and data sets for model evaluation. For this study, all model experiments are run on a mesh with enhanced horizontal grid resolution on the continental shelves of the Southern Ocean, especially in the Weddell Sea. The horizontal resolution ranges from $4 \mathrm{~km}$ in the southern Weddell Sea to $\sim 80 \mathrm{~km}$ at the outer edge of the Weddell Gyre and increases to $>100 \mathrm{~km}$ outside of the Southern Ocean (Supplementary Fig. 14). The vertical is divided into 99 unevenly spaced $z$ levels, of which 21 depth levels are situated below $2000 \mathrm{~m}$. The time step in our simulations is four minutes. We run transient simulations with FESOM-REcoM for the years 1950-2100. At the ocean surface, we force the model with output from the AWI Climate Model (AWI-CM) produced for the "Coupled Model Intercomparison Project Phase 6 (CMIP6) ${ }^{159}$. We use 3-hourly output of atmospheric momentum, radiation, and freshwater fluxes and daily output of terrestrial freshwater runoff from the first ensemble member of the historical simulation until 2014 and from the SSP5-8.5 scenario simulation thereafter. We note that the SSP5-8.5 scenario assumes a continuously high usage of fossil fuel for the evolution of $\mathrm{CO}_{2}$ emissions ${ }^{72}$, thereby assuming weaker climate protection policies for the $21^{\text {st }}$ century than currently in place ${ }^{73}$. Nonetheless, the atmospheric $\mathrm{CO}_{2}$ concentrations and the resulting future climate suggested by Earth System Models under the SSP5-8.5 scenario are possible even under lower-emission scenarios as a result of the large uncertainty associated with carboncycle feedbacks in these models ${ }^{73}$. Atmospheric $\mathrm{pCO}_{2}$ levels are taken from Meinshausen et al.$^{[74}$ for the historical period 1950-2014 and from O'Neill et al ${ }^{72}$ for the period 2015-2100, consistent with the time series used in the CMIP6 experiments. In our experiments, the physical tracers are initialized with FESOM output from the historical simulation of the AWI-CM and the biogeochemical tracers with REcoM output from an existing simulation for the "Regional Carbon Cycle Assessment and Processes 2 (RECCAP2)" project (unpublished). Thereby, at the start of our simulations, the physical and biogeochemical tracers have been spun up for 850 years (FESOM) and 100 years (REcoM), respectively.

For this study, two model experiments were performed: $\operatorname{sim} A$ is forced with varying climate and varying atmospheric $\mathrm{pCO}_{2}$ levels as described above, whereas $\operatorname{sim} B$ is forced by repeating the atmospheric conditions of the year 1950 (atmospheric $\mathrm{pCO}_{2} ; 312.82 \mathrm{ppm}^{74}$ ) and 1955 (all other variables), allowing for an assessment of the model drift. The year 1955 was chosen aiming to 1) minimize the warming signal in the chosen year and 2) represent "normal" atmospheric conditions, which we identify by assessing the phase of the Southern Annular Mode and EI Niño Southern Oscillation in the first 20 years of the forcing. We acknowledge that in the control simulation $\operatorname{sim} B$, the deep-ocean carbon inventory in the southern Weddell Sea is not in a steady state at the start of the analysis period in 1980 (Fig. 2a), which can be attributed to the spin-up procedure. In particular, atmospheric $\mathrm{CO}_{2}$ concentrations have risen from the preindustrial $278 \mathrm{ppm}$ to $313 \mathrm{ppm}$ during the spin-up, and another $\sim 100$ years are needed in $\operatorname{sim} B$ for the deep-ocean carbon inventory to reach quasi-equilibrium with this atmospheric $\mathrm{CO}_{2}$ level (Fig. $2 \mathrm{a}$ ). However, this does not affect the conclusions drawn in this study because upper ocean processes are close to equilibrium already in 1980 (see Fig. 2r and Supplementary Fig. 1) and because the climate-change signal in $\operatorname{sim} A$ exceeds the drift in $\operatorname{sim} B$ by far also for the deep ocean (Fig.22a).

Model output is generally stored at monthly frequency, with physical flux output being only available for selected decades, namely between 1980-1999 and 2080-2099. For the budget analysis of the deep-ocean 
carbon inventory in the southern Weddell Sea, vertical mixing fluxes are inferred from the change in the total carbon inventory, biological fluxes (see above), and the remaining physical flux components (lateral and vertical advection, horizontal diffusion, fluxes from the Gent-McWilliams parametrization, and the stabilization of the Taylor-Galerkin advection scheme ${ }^{54}$ ). For model evaluation, we use available ship-observations of dissolved inorganic carbor ${ }^{75}$ and temperature \& salinity ${ }^{12}$ (see Supplementary Fig. 11,12 \& 15). Weddell Sea Deep Water (WSDW) and Weddell Sea Bottom Water (WSBW) in FESOM-REcoM are defined as waters with a potential temperature $<-0.2^{\circ} \mathrm{C}$ and a practical salinity $>34.55$, and we do not distinguish these two water masses in this study. The thresholds used here differ slightly from those in Fahrbach et al. ${ }^{17}$, who used $0^{\circ} \mathrm{C}$ as the temperature threshold and 34.6 and 34.63 as the salinity thresholds to distinguish WSDW and WSBW, respectively, from Warm Deep Water (WDW). The definition was chosen here to best reflect the simulated water mass structure both south of and at the transect SR4, thereby accounting for a slight fresh bias in the focus region and a cold bias in the WDW core in the model (Supplementary Fig. 11 \& 12).

Age tracer. Our model experiments include an age tracer, which is initialized at zero everywhere in the model domain. Over the course of the simulations, the age of a given water parcel increases accordingly and is only reset when it comes in contact with the surface, with surface here being either the air-ocean, sea ice-ocean, or ice shelf-ocean interface. The age tracer is advected and mixed as any other model tracer, implying that the age of a water parcel can also decline (increase) by mixing with a water parcel of lower (higher) age, i.e., if the latter water parcel has been in touch with the surface more recently (longer ago) than the former. Hence, based on a water parcel's age $a$, we calculate the ventilated fraction $\epsilon$ [\%] of this water parcel at time $t$ of the simulation as

$$
\epsilon(t)=100 \cdot \frac{t-a_{t}}{t}
$$

With this definition, a given water parcel with an age corresponding to the simulation time $t$ is not ventilated at all, whereas an age of zero corresponds to $100 \%$ ventilated water. Consequently, a comparison of the age-tracer based ventilated fractions of bottom waters in the southern Weddell Sea between the 2090s and 1990 s reveals changes in the exchange of these waters with the ocean surface.

Water mass transformation framework. Here, we are mostly interested in the formation of dense waters on the Weddell Sea continental shelves. To that aim, we assess water mass transformations due to surface buoyancy fluxes on the continental shelf south of the WOCE transect SR4, which connects the tip of the Antarctic Peninsula with the eastern Weddell Sea (Fig. 1), and in the eastern Weddell Sea (see Fig. 6 and Supplementary Fig. 10 for the exact location of both shelf regions). Any change in the volume of waters in a given density class between the surface outcrop of these waters south of the transect SR4 and their volume flux across the transect SR4 is due to either 1) a change in the transport of this density class across SR4, 2) diapycnal mixing fluxes in the ocean interior, or 3) surface transformations causing a lateral diapycnal flux ${ }^{76}$. In this context, the water mass transformation (WMT) framework relates the density distribution at the ocean surface to buoyancy fluxes, providing a framework to relate the formation of dense waters to heat fluxes or freshwater fluxes from evaporation minus precipitation, sea ice, or ice shelves ${ }^{4061.64}$.

Discretizing the surface density $(\rho)$ field into bins of $0.025 \mathrm{~kg} \mathrm{~m}^{-3}$, heat fluxes $Q_{n e t}$ and freshwater fluxes $F_{n e t}$ transform water masses in the density bin $\rho_{k}$ with a rate $\Omega$ [Sv] at any time $t$ at the atmosphere-ocean or ice-ocean interface, following

$$
\Omega\left(\rho_{k}, t\right)=-\frac{1}{\rho_{k+1}-\rho_{k}} \iint_{A} \frac{\alpha Q_{n e t}}{\rho_{0} C_{p}} d A+\frac{1}{\rho_{k+1}-\rho_{k}} \iint_{A} \frac{\beta S F_{n e t}}{\rho_{0}} d A .
$$

Here, $A$ is the outcrop area between the density bins $k$ and $k+1, \alpha$ and $C_{p}$ are the thermal expansion coefficient and the heat capacity, respectively, $\beta$ and $S$ are the haline contraction coefficient and the surface salinity, respectively, $\rho_{0}$ is the reference density, and $F_{n e t}$ is composed of freshwater fluxes between atmosphere and ocean $\left(F_{\text {Atm } \rightarrow \text { Ocean }}\right)$, sea ice and ocean $\left(F_{\text {Seaice } \rightarrow \text { Ocean }}\right)$, and ice shelves and ocean $\left(F_{\text {Iceshelf } \rightarrow \text { Ocean }}\right)$ :

$$
F_{\text {net }}=F_{\text {Atm } \rightarrow \text { Ocean }}+F_{\text {Seaice } \rightarrow \text { Ocean }}+F_{\text {Iceshel } \rightarrow \text { Ocean }} .
$$

The convergence (divergence) of waters in a given density class implies downwelling (upwelling) of these to satisfy mass continuity. We use the potential density referenced to $2000 \mathrm{dbar}\left(\rho_{2}\right)$ as the density coordinate and display the density anomaly throughout this manuscript $\left(\sigma_{2}=\rho_{2}-1000 \mathrm{~kg} \mathrm{~m}^{-3}\right)$. While different density coordinates have been used by other authors in the pas $[40[63$, the qualitative results presented here are insensitive to this choice. Here, we compute WMT rates in the southern Weddell Sea based on monthly model output for the 1990s and 2090s. 


\section{Acknowledgments}

This project has received funding from the Initiative and Networking Fund of the Helmholtz Association (Helmholtz Young Investigator Group Marine Carbon and Ecosystem Feedbacks in the Earth System [MarESys], grant number VH-NG-1301), from the European Union's Horizon 2020 research and innovation programme under grant agreement No 820989 (project COMFORT), and from the Helmholtz Climate Initiative REKLIM (Regional Climate Change), a joint research project of the Helmholtz Association of German research centres (HGF). The work reflects only the authors' view; the European Commission and their executive agency are not responsible for any use that may be made of the information the work contains. Computing resources were provided by the North-German Supercomputing Alliance (HLRN).

\section{Data availability}

The model output needed to reproduce the results presented here will be uploaded to PANGAEA upon acceptance of the manuscript. Codes and full model output are available upon request from the corresponding author.

\section{Author contributions}

C.N., J.H., and M.H. conceived the study. C.N. set up the model simulations, with help from R.T. and J.H. C.N. performed the analysis. All authors contributed to the interpretation of the results and the writing of the manuscript.

\section{Competing interests}

The authors declare no competing interests.

\section{References}

[1] Marshall, J. and Speer, K. "Closure of the meridional overturning circulation through Southern Ocean upwelling". Nature Geoscience 5 (2012), 171-180. DOI: 10.1038/ngeo1391.

[2] Sarmiento, J. L. and Toggweiler, J. R. "A new model for the role of the oceans in determining atmospheric $\mathrm{pCO}_{2}$ ". Nature 308 (1984), 621-624. DOI: 10.1038/308621a0

[3] Siegenthaler, U. and Wenk, Th. "Rapid atmospheric $\mathrm{CO}_{2}$ variations and ocean circulation". Nature 308 (1984), 624-626. DOI: 10.1038/308624a0.

[4] Toggweiler, J. R. "Variation of atmospheric $\mathrm{CO}_{2}$ by ventilation of the ocean's deepest water". Paleoceanography 14 (1999), 571-588. DOI: 10.1029/1999PA900033

[5] Marinov, I. et al. "The Southern Ocean biogeochemical divide." Nature 441 (2006), 964-7. DOI: 10 . 1038/nature04883

[6] DeVries, T., Primeau, F., and Deutsch, C. "The sequestration efficiency of the biological pump". Geophysical Research Letters 39 (2012), n/a-n/a. DOI: 10.1029/2012GL051963.

[7] de Lavergne, C. et al. "Cessation of deep convection in the open Southern Ocean under anthropogenic climate change". Nature Climate Change 4 (2014), 278-282. DOI: 10.1038/nclimate2132

[8] Heuzé, C. "Antarctic Bottom Water and North Atlantic Deep Water in CMIP6 models". Ocean Science 17 (2021), 59-90. DOI: $10.5194 /$ os-17-59-2021

[9] Vernet, M. et al. "The Weddell Gyre, Southern Ocean: Present Knowledge and Future Challenges". Reviews of Geophysics 57 (2019), 623-708. DOI: 10.1029/2018RG000604

[10] Jacobs, S. S. "Bottom water production and its links with the thermohaline circulation". Antarctic Science 16 (2004), 427-437. DOI: 10.1017/S095410200400224X.

[11] Meredith, M. P. "Replenishing the abyss". Nature Geoscience 6 (2013), 166-167. DOI: 10 . $1038 /$ ngeo1743.

[12] Driemel, A. et al. "From pole to pole: 33 years of physical oceanography onboard R/V Polarstern". Earth System Science Data 9 (2017), 211-220. DOI:10.5194/essd-9-211-2017. 
[13] Gill, A. E. "Circulation and bottom water production in the Weddell Sea". Deep Sea Research and Oceanographic Abstracts 20 (1973), 111-140. DOI: 10.1016/0011-7471(73)90048-X.

[14] Orsi, A. H., Johnson, G.C., and Bullister, J.L. "Circulation, mixing, and production of Antarctic Bottom Water". Progress in Oceanography 43 (1999), 55-109. Dol: 10.1016/S0079-6611 (99) 00004-X.

[15] Nicholls, K. W. et al. "Ice-ocean processes over the continental shelf of the southern Weddell Sea, Antarctica: A review". Reviews of Geophysics 47 (2009), RG3003. DOI: 10.1029/2007RG000250.

[16] Akhoudas, C. et al. "Ventilation of the abyss in the Atlantic sector of the Southern Ocean". Scientific Reports 11 (2021), 6760. DOI: 10.1038/s41598-021-86043-2.

[17] Fahrbach, E. et al. "Transport and structure of the Weddell Gyre". Ann. Geophys. 12 (1994), 840-855. DOI: $10.1007 / \mathrm{s} 00585-994-0840-7$.

[18] Reeve, K. A. et al. "Horizontal circulation and volume transports in the Weddell Gyre derived from Argo float data". Progress in Oceanography 175 (2019), 263-283. DoI: 10.1016/j . pocean. 2019.04.006.

[19] Foldvik, A., Gammelsrød, T., and Tørresen, T. Circulation and water masses on the southern Weddell Sea shelf. Oceanology of the Antarctic Continental Shelf, Vol. 43, 5-20. American Geophysical Union, 1985.

[20] Fahrbach, E. et al. "Suppression of bottom water formation in the southeastern Weddell sea". Deep Sea Research Part I: Oceanographic Research Papers 41 (1994), 389-411. DOI: 10 . 1016/09670637(94) 90010-8

[21] Fahrbach, E. et al. "Formation and discharge of deep and bottom water in the northwestern Weddell Sea". Journal of Marine Research 53 (1995), 515-538. DOI: 10.1357/0022240953213089.

[22] Meredith, M. P. et al. "On the sources of Weddell Gyre Antarctic Bottom Water". Journal of Geophysical Research: Oceans 105 (2000), 1093-1104. DOI: 10.1029/1999JC900263.

[23] Gordon, A. L., Visbeck, M., and Huber, B. "Export of Weddell Sea Deep and Bottom Water". Journal of Geophysical Research: Oceans 106 (2001), 9005-9017. DOI: 10.1029/2000jc000281.

[24] Huhn, O. et al. "Evidence of deep- and bottom-water formation in the western Weddell Sea". Deep Sea Research Part II: Topical Studies in Oceanography 55 (2008), 1098-1116. DOI: 10.1016/j . dsr2 . 2007.12.015.

[25] Kerr, R. et al. "Three decades of deep water mass investigation in the Weddell Sea (1984-2014): Temporal variability and changes". Deep Sea Research Part II: Topical Studies in Oceanography 149 (2018), 70-83. DOI: 10.1016/j.dsr2.2017.12.002.

[26] Abrahamsen, E. P. et al. "Stabilization of dense Antarctic water supply to the Atlantic Ocean overturning circulation". Nature Climate Change 9 (2019). DOI: 10.1038/s41558-019-0561-2.

[27] Gordon, A. L., Huber, Bruce A., and Abrahamsen, E. Povl. "Interannual Variability of the Outflow of Weddell Sea Bottom Water". Geophysical Research Letters 47 (2020), TBD. DOI:10.1029/2020GL087014.

[28] Fahrbach, E. et al. "Warming of deep and abyssal water masses along the Greenwich meridian on decadal time scales: The Weddell gyre as a heat buffer". Deep Sea Research Part II: Topical Studies in Oceanography 58 (2011), 2509-2523. DOI: 10.1016/j.dsr2.2011.06.007.

[29] Hellmer, H. H. et al. "On the freshening of the northwestern Weddell Sea continental shelf". Ocean Science 7 (2011), 305-316. DOI: 10.5194/os-7-305-2011.

[30] Meredith, M. P. et al. "Synchronous intensification and warming of Antarctic Bottom Water outflow from the Weddell Gyre". Geophysical Research Letters 38 (2011), n/a-n/a. DOI:10.1029/2010GL046265.

[31] Jullion, L. et al. "Decadal Freshening of the Antarctic Bottom Water Exported from the Weddell Sea". Journal of Climate 26 (2013), 8111-8125. DOI: 10.1175/JCLI-D-12-00765.1.

[32] Meredith, M. P. et al. "Dense waters of the Weddell and Scotia Seas: recent changes in properties and circulation". Philosophical Transactions of the Royal Society A: Mathematical, Physical and Engineering Sciences 372 (2014), 20130041. DOI: 10.1098/rsta.2013.0041.

[33] Strass, V. H. et al. "Multidecadal Warming and Density Loss in the Deep Weddell Sea, Antarctica". Journal of Climate 33 (2020), 9863-9881. DOI: 10.1175/JCLI-D-20-0271.1.

[34] Huhn, O. et al. "Decline of deep and bottom water ventilation and slowing down of anthropogenic carbon storage in the Weddell Sea, 1984-2011". Deep Sea Research Part I: Oceanographic Research Papers 76 (2013), 66-84. DOI:10.1016/j.dsr.2013.01.005. 
[35] Purich, A. and England, M. H. "Historical and Future Projected Warming of Antarctic Shelf Bottom Water in CMIP6 Models". Geophysical Research Letters 48 (2021), 1-15. DOI: 10.1029/2021GL092752.

[36] Heuzé, C. et al. "Changes in Global Ocean Bottom Properties and Volume Transports in CMIP5 Models under Climate Change Scenarios". Journal of Climate 28 (2015), 2917-2944. DOI: 10.1175/JCLI-D14-00381.1

[37] Heuzé, C. et al. "Southern Ocean bottom water characteristics in CMIP5 models". Geophysical Research Letters 40 (2013), 1409-1414. DOI:10.1002/grl.50287.

[38] DeConto, R. M. and Pollard, D. "Contribution of Antarctica to past and future sea-level rise". Nature $\mathbf{5 3 1}$ (2016), 591-597. DOI: 10.1038/nature17145.

[39] Lago, V. and England, M. H. "Projected Slowdown of Antarctic Bottom Water Formation in Response to Amplified Meltwater Contributions". Journal of Climate 32 (2019), 6319-6335. DOI:10.1175/JCLID-18-0622.1.

[40] Moorman, R., Morrison, A. K., and McC. Hogg, A. "Thermal Responses to Antarctic Ice Shelf Melt in an Eddy-Rich Global Ocean-Sea Ice Model". Journal of Climate 33 (2020), 6599-6620. DOI: 10.1175/ JCLI-D-19-0846.1.

[41] Hellmer, H. H. et al. "Twenty-first-century warming of a large Antarctic ice-shelf cavity by a redirected coastal current". Nature 485 (2012), 225-228. DOI: 10.1038/nature11064.

[42] Timmermann, R. and Hellmer, H. H. "Southern Ocean warming and increased ice shelf basal melting in the twenty-first and twenty-second centuries based on coupled ice-ocean finite-element modelling". Ocean Dynamics 63 (2013), 1011-1026. DOI: 10.1007/s10236-013-0642-0.

[43] Hellmer, H. H. et al. "The Fate of the Southern Weddell Sea Continental Shelf in a Warming Climate". Journal of Climate 30 (2017), 4337-4350. DOI: 10.1175/JCLI-D-16-0420.1.

[44] Timmermann, R. and Goeller, S. "Response to Filchner-Ronne Ice Shelf cavity warming in a coupled ocean-ice sheet model - Part 1: The ocean perspective". Ocean Science 13 (2017), 765-776. DOI: 10.5194/os-13-765-2017.

[45] Naughten, K. A. et al. "Future Projections of Antarctic Ice Shelf Melting Based on CMIP5 Scenarios". Journal of Climate 31 (2018), 5243-5261. DOI: 10.1175/JCLI-D-17-0854.1.

[46] Naughten, K. A. et al. "Two-timescale response of a large Antarctic ice shelf to climate change". Nature Communications 12 (2021), 1991. DOI: 10.1038/s41467-021-22259-0.

[47] Hoppema, M. et al. "Annual uptake of atmospheric $\mathrm{CO}_{2}$ by the Weddell Sea derived from a surface layer balance, including estimations of entrainment and new production". Journal of Marine Systems 19 (1999), 219-233. DOI: 10.1016/S0924-7963(98)00091-8.

[48] Hoppema, M. "Weddell Sea turned from source to sink for atmospheric $\mathrm{CO}_{2}$ between pre-industrial time and present". Global and Planetary Change 40 (2004), 219-231. DOI: 10.1016/j . gloplacha. 2003.08.001.

[49] van Heuven, S. M. A. C. et al. "Direct observation of increasing $\mathrm{CO}_{2}$ in the Weddell Gyre along the Prime Meridian during 1973-2008". Deep Sea Research Part II: Topical Studies in Oceanography 58 (2011), 2613-2635. DOI: $10.1016 / j . d s r 2.2011 .08 .007$.

[50] Brown, P. J. et al. "Carbon dynamics of the Weddell Gyre, Southern Ocean". Global Biogeochemical Cycles 29 (2015), 288-306. DOI: 10.1002/2014GB005006.

[51] MacGilchrist, G. A. et al. "Reframing the carbon cycle of the subpolar Southern Ocean". Science Advances 5 (2019), 1-9. DOI:10.1126/sciadv. aav6410.

[52] Hauck, J. et al. "On the Southern Ocean $\mathrm{CO}_{2}$ uptake and the role of the biological carbon pump in the $21^{\text {st }}$ century". Global Biogeochemical Cycles 29 (2015), 1451-1470. DOI: 10.1002/2015GB005140.

[53] Hauck, J. et al. "Seasonally different carbon flux changes in the Southern Ocean in response to the southern annular mode". Global Biogeochemical Cycles 27 (2013), 1236-1245. DOI: 10.1002/ 2013GB004600.

[54] Wang, Q. et al. "The Finite Element Sea Ice-Ocean Model (FESOM) v.1.4: formulation of an ocean general circulation model". Geoscientific Model Development 7 (2014), 663-693. DOI: 10.5194/gmd7-663-2014.

[55] Danilov, S. et al. "Finite-Element Sea Ice Model (FESIM), version 2". Geoscientific Model Development 8 (2015), 1747-1761. DOI: 10.5194/gmd-8-1747-2015 
[56] Schourup-Kristensen, V. et al. "Progress in Oceanography Arctic Ocean biogeochemistry in the high resolution FESOM1.4-REcoM2 model”. Progress in Oceanography 168 (2018), 65-81. DOI: 10.1016/ j.pocean.2018.09.006.

[57] Karakus, O. et al. "Modeling the Impact of Macrozooplankton on Carbon Export Production in the Southern Ocean". Journal of Geophysical Research - Oceans in review (2021), n.a. DOI: n.a.

[58] Timmermann, R., Wang, Q., and Hellmer, H.H. "Ice-shelf basal melting in a global finite-element seaice/ice-shelf/ocean model". Annals of Glaciology 53 (2012), 303-314. DOI:10.3189/2012AoG60A156.

[59] Semmler, T. et al. "Simulations for CMIP6 With the AWI Climate Model AWI-CM-1-1". Journal of Advances in Modeling Earth Systems 12 (2020), 1-34. DOI: 10.1029/2019MS002009.

[60] Anderson, R. F. et al. "Wind-Driven Upwelling in the Southern Ocean and the Deglacial Rise in Atmospheric $\mathrm{CO}_{2}$ ". Science 323 (2009), 1443-1448. DOI: 10.1126/science.1167441.

[61] Walin, G. "On the relation between sea-surface heat flow and thermal circulation in the ocean". Tellus 34 (1982), 187-195. DOI: 10.1111/j.2153-3490.1982.tb01806.x.

[62] Marshall, J., Jamous, D., and Nilsson, J. "Reconciling thermodynamic and dynamic methods of computation of water-mass transformation rates". Deep Sea Research Part I: Oceanographic Research Papers 46 (1999), 545-572. DOI: 10.1016/S0967-0637(98)00082-X.

[63] Abernathey, R. P. et al. "Water-mass transformation by sea ice in the upper branch of the Southern Ocean overturning". Nature Geoscience 9 (2016), 596-601. DOI: 10.1038/ngeo2749.

[64] Jeong, H. et al. "Impacts of Ice-Shelf Melting on Water-Mass Transformation in the Southern Ocean from E3SM Simulations". Journal of Climate 33 (2020), 5787-5807. DOI: 10 . 1175/ JCLI - D - 190683.1

[65] Rignot, E et al. "Ice-Shelf Melting Around Antarctica". Science 341 (2013), 266-270. DOI: 10.1126/ science.1235798.

[66] Weber, T. et al. "Deep ocean nutrients imply large latitudinal variation in particle transfer efficiency". Proceedings of the National Academy of Sciences 113 (2016), 8606-8611. DOI: 10 . 1073 / pnas . 1604414113 .

[67] Usbeck, R. et al. "Shallow remineralization in the Weddell Gyre". Geochemistry, Geophysics, Geosystems 3 (2002), 1-18. DOI: 10.1029/2001GC000182.

[68] Nissen, C. and Vogt, M. "Factors controlling the competition between Phaeocystis and diatoms in the Southern Ocean and implications for carbon export fluxes". Biogeosciences 18 (2021), 251-283. DOI: 10.5194/bg-18-251-2021.

[69] Jong, J. de et al. "Natural iron fertilization of the Atlantic sector of the Southern Ocean by continental shelf sources of the Antarctic Peninsula". Journal of Geophysical Research: Biogeosciences 117 (2012). DOI: $10.1029 / 2011$ JG001679.

[70] Lenton, T. M. et al. "Tipping elements in the Earth's climate system". Proceedings of the National Academy of Sciences 105 (2008), 1786-1793. ISSN: 0027-8424. DOI: 10.1073/pnas.0705414105.

[71] Schaffer, J. et al. "A global, high-resolution data set of ice sheet topography, cavity geometry, and ocean bathymetry". Earth System Science Data 8 (2016), 543-557. Dol: 10.5194/essd-8-543-2016.

[72] O'Neill, B. C. et al. "The Scenario Model Intercomparison Project (ScenarioMIP) for CMIP6". Geoscientific Model Development 9 (2016), 3461-3482. DOI: 10.5194/gmd-9-3461-2016.

[73] IPCC. Climate Change 2021: The Physical Science Basis. Contribution of Working Group I to the Sixth Assessment Report of the Intergovernmental Panel on Climate Change. Ed. by V. Masson-Delmotte et al. Cambridge University Press, 2021.

[74] Meinshausen, M. et al. "Historical greenhouse gas concentrations for climate modelling (CMIP6)". Geoscientific Model Development 10 (2017), 2057-2116. DOI: 10.5194/gmd-10-2057-2017.

[75] Olsen, A. et al. "The Global Ocean Data Analysis Project version 2 (GLODAPv2) - an internally consistent data product for the world ocean”. Earth System Science Data 8 (2016), 297-323. DOI: 10.5194/ essd-8-297-2016.

[76] Downes, S. M. et al. "An assessment of Southern Ocean water masses and sea ice during 1988-2007 in a suite of interannual CORE-II simulations". Ocean Modelling 94 (2015), 67-94. DOI: 10 .1016/j . ocemod.2015.07.022. 


\section{Supplementary Files}

This is a list of supplementary files associated with this preprint. Click to download.

- Nissen2021COMFORT1Supplementv20210924SUBMITTED.pdf 